\title{
La estabilidad laboral en la ley de reforma magisterial n 29944 peruana en comparación con las legislaciones de Argentina, Chile, Colombia y México
}

\section{Labor stability in the magisterial reform law no. 29944 peruana in comparison with the laws of Argentina, Chile, Colombia and Mexico}

\author{
Quispe Cansaya, Isidro Grimaniel; Pineda Ancco, Javier Sócrates \\ Pineda Ancco, Ferdinand; Santillán Aching, Omar \\ Universidad Nacional Del Altiplano; Universidad Peruana Unión - Filial Juliaca
}

\begin{abstract}
Resumen
Durante los últimos años, en Latinoamérica, se está fortaleciendo la idea de la calidad de la educación. Un aspecto fundamental es el papel de los docentes en los resultados educativos. En muchos países, preocupados por tales circunstancias, las agendas políticas apuntaron a resolver los problemas de formación profesional inicial y en servicio, ingreso, permanencia y a plantear mecanismos de evaluación que den cuenta la labor del maestro. Es así, que se encontró gran similitud o semejanza entre las legislaciones de Perú, Colombia y México, al parecer tuvieron la misma intensión; puesto que, existe mucha igualdad en los artículos relacionados con el ingreso, permanencia y sobre todo el derecho a la estabilidad laboral; pues éstos se circunscriben únicamente a la aprobación de una evaluación de desempeño, vulnerando así dicho principio. Del mismo modo, se pudo establecer que existe una marcada diferencia con las legislaciones de Argentina y Chile; pues dentro de sus ordenamientos jurídicos, aún consideran los aportes de sus estatutos anteriores, pues estos, aún brindan una garantía y protección en su derecho a la estabilidad laboral. La investigación fue con un enfoque cualitativo y bajo un estudio comparativo.
\end{abstract}

Palabras claves: Análisis comparativo, diferencias, derecho al trabajo, derecho constitucional, doctrina, estabilidad laboral, permanencia en el tiempo, semejanzas, seguridad jurídica.

\section{Abstract}

This work was focused on the comparative study of the right to stability in the Magisterial Reform Act No. 29944 (Peru) and the laws of Argentina, Chile, Colombia and Mexico. In recent years, in Latin America, it is strengthening the idea of the quality of education. A key aspect is the role of teachers in educational outcomes. In many countries, concerned about such circumstances, political agendas aimed at resolving the problems of initial training and in service, entry, stay, wages, etc., and to propose appropriate evaluation mechanisms that take into account the work of the teacher. In this situation they made legitimately collective protests because they feel that their working conditions are at risk of being violated. It is so much similarity or similarity found between the laws of Peru, Colombia and Mexico apparently had the same intention; since there is much equality in drafting them and even more in relation to articles related entry, stay and especially the right to job security; since they are limited only to the approval of a performance, thus violating that principle. Similarly, it was established that there is a marked difference with the laws of Argentina and Chile; because within their legal systems, still they consider the contributions of its previous statutes, as these still provide a guarantee and protection of their right to job security and gives them confidence for the exercise of its function.

Key words: Comparative analysis, differences, right to work, constitutional law, arbitrary dismissal, doctrine, job stability, permanence in time, similarities, legal certainty.

\section{Introducción}

En esta última década, se han incrementado en América Latina, diversas investigaciones e informes referidos a la problemática que encierra al maestro de escuela. El sistema educativo ha pasado por una serie de reformas que ha abarcado los principales campos de acción de la política educativa. Y por lo tanto consideramos que, en el mundo actual, están íntimamente vinculados el tema económico con lo laboral y, que el derecho al acceso al trabajo depende fundamentalmente de las políticas que adopten los gobiernos para promover las condiciones económicas sociales que aseguren la oportunidad de una ocupación útil.

Es así, que se pone de manifiesto el "derecho al trabajo" y como manifestación legitima, el derecho a la "estabilidad laboral"; es decir, cuando la persona accedió a un puesto y lo viene desarrollando, igualmente la doctrina sostiene que tal trabajador tiene el derecho a "conservar el trabajo". (Marcenaro, 1995, p. 45 y 47). 
Javier Neves, sostiene que el derecho a la conservación del empleo supone la prohibición del despido arbitrario. En esta línea de pensamiento, Neves considera que "la conservación del empleo que supone el derecho al trabajo goza de preceptividad inmediata. De este modo, cualquier extinción del vínculo laboral que lesione tal derecho podría ser contrarrestada con una acción de amparo. Así ocurriría en el caso de un despido arbitrario, aunque no vulnerara otros derechos constitucionales... "Sin embargo reconoce que la existencia del artículo 27 de la Constitución que delega a la ley se concrete la protección contra el despido arbitrario, le origina determinadas incertidumbres" (Neves, 2001, p. 25).

El derecho como un área del conocimiento, está dentro de las ciencias sociales; en esa lógica, la investigación jurídica recoge sus lineamientos. Este estudio comparativo entre la Ley de Reforma Magisterial No 29944 del Perú con las legislaciones del derecho comparado, tiene la orientación de acuerdo a los criterios de una investigación cualitativa, por cuanto el objeto de estudio implica básicamente un análisis e interpretación, como es la norma jurídica, concernientes a la regulación de la Estabilidad Laboral en el Perú y en los países de Latinoamérica, con la finalidad de establecer las semejanzas y diferencias en su tratamiento y los aspectos que fueron considerados para el desarrollo profesional del profesorado.

Creemos que las conclusiones de esta investigación son de suma importancia puesto que nos permitirá abordar y establecer algunas conclusiones orientadas a esclarecer y determinar si las legislaciones en Latinoamérica con respecto a la legislación peruana, garantizan o no la estabilidad laboral para los profesores. Para lo cual nos planteamos las siguientes interrogantes: ¿Cuál es la regulación jurídica del derecho a la estabilidad laboral en la Ley de Reforma Magisterial No 29944 (Perú) con las legislaciones de Argentina, Chile, Colombia y México? Así mismo ¿Cuáles son las semejanzas y diferencias sobre el derecho a la estabilidad laboral en la Ley de Reforma Magisterial No 29944 (Perú) con las legislaciones del derecho comparado? Para lo cual se planteó el objetivo general de: Analizar la regulación jurídica del derecho a la estabilidad laboral en la Ley de Reforma Magisterial N² 29944 (Perú) con las legislaciones de Argentina, Chile, Colombia y México. Y como objetivo específico: Establecer las semejanzas y diferencias con las legislaciones del derecho comparado.

\section{Metodología}

La presente investigación es de tipo cualitativo, que tiene como característica la flexibilidad, tanto en la formulación del proyecto de investigación, como en el recojo de información. "El investigador inicia un estudio con un cierto grado de flexibilidad con respecto al objeto de investigación y a lo que se puede aprender de éste. El investigador comienza por seleccionar casos y lugares relevantes para la descripción de la investigación y a continuación identifica los "conceptos guía", aclara los principales conceptos y categorías". (Ragin, 1994, p. 149). El método que corresponde a esta investigación es comparativo; el mismo que consiste en recoger información sobre las diferencias y semejanzas de las legislaciones de Perú, Argentina, Colombia, Chile y México, en lo referente al derecho a la estabilidad laboral. "Este método intenta establecer nuevas categorías o clasificaciones que recubran las diferencias y similitudes encontradas" (Peña, 2011, p. 35)

\section{Análisis de la estabilidad laboral}

\section{Una mirada regional a la profesión docente}

En América Latina y el Caribe existen aproximadamente 6.4 millones de profesores para la educación primaria y secundaria (UNESCO, 2012). El estudio revela la heterogeneidad del profesorado, pero también capta diferencias y recurrencias en el nivel regional. La profesión docente se regula en la mayoría de los países por los estatutos docentes, que son el instrumento que da legitimidad a la actividad de enseñanza y establecen derechos y obligaciones (Vaillant, D. y Rossel, C., 2006).

\section{La estabilidad laboral}

La estabilidad consiste en el derecho que un trabajador tiene a conservar su puesto indefinidamente, de no incurrir en faltas previamente determinadas o de no acaecer en especialísimas circunstancias. Garantiza los ingresos del trabajador en forma directa, lo que es medio indispensable de satisfacción de necesidades del núcleo familiar. El sentido de la estabilidad es proteger al trabajador de los despidos arbitrarios. La estabilidad laboral constituye más que un escudo protector, el escudo "reparador" del principio de continuidad de la relación laboral que, "...sólo se debe disolver válidamente cuando exista algún motivo justificado." (Plá, 1968)

\section{Antecedentes}

La carta de la Organización de Estados Americanos, en su artículo 28, proclama que el hombre, mediante su trabajo, tiene el derecho de alcanzar su bienestar material y su desarrollo espiritual en condiciones de libertad, dignidad, igualdad de oportunidades y seguridad económica.

La Organización Internacional del Trabajo (OIT), que desde el año 1919, ha sido el ente rector de la regulación de los temas laborales en el mundo. Y el tema de la estabilidad laboral, no ha sido ajeno y ella fue contemplada en el convenio de la OIT. Número 158 la misma que no fue ratificada por el Perú.

El artículo 42 de la Constitución de 1979 en la que se inspira la norma vigente, establecía lo siguiente: "....El trabajo es un derecho y un deber social. Corresponde al Estado promover las condiciones económicas y sociales que eliminen la pobreza y aseguren por igual a los habitantes de la República la oportunidad de una ocupación útil y que los protejan contra el desempleo y el 
subempleo en cualquiera de sus manifestaciones. En efecto, se reconocían expresamente los principios de igualdad de trato, indubio pro operario, irrenunciabilidad y retroactividad de las leyes si son favorables a los trabajadores.

La Constitución de 1979 reconoció, por vez primera, el derecho de estabilidad laboral o el principio de continuidad laboral en sus dos modalidades. La estabilidad laboral de entrada y la de salida. Por la primera, se aseguraba que el trabajador tuviera derecho a adquirir una estabilidad de entrada -una excepción era el período de prueba o los contratos a plazo fijo- y otra era la estabilidad de salida -protección contra el despido arbitrario-. (Toyama, 2001).

El artículo 22 de la CP vigente establece que "El trabajo es un deber y un derecho. Es base del bienestar social y un medio de realización de la persona “. Existen otras disposiciones constitucionales. La primera de ellas es el artículo 23 CP “el trabajo, en sus diversas modalidades, es objeto de atención prioritaria del Estado (...). El Estado promueve condiciones para el progreso social y económico, en especial mediante políticas de fomento del empleo productivo y de educación para el trabajo".

Adicionalmente existen al menos otras dos disposiciones constitucionales del derecho al trabajo. La primera de ellas es el artículo $27 \mathrm{CP}$ en la que se ha establecido que "la ley otorga al trabajador adecuada protección contra el despido arbitrario". Y la segunda norma constitucional a considerar es la Cuarta disposición final y transitoria en la que se ha mandado que "las normas relativas a los derechos y a las libertades que la Constitución reconoce se interpretan de conformidad con la Declaración Universal de Derechos Humanos y con los tratados y acuerdos internacionales sobre las mismas materias ratificados por el Perú”.

\section{Evaluación del desempeño docente}

La evaluación de los docentes no ha sido en muchos países de América Latina, un tema prioritario, lo cual no significa que no exista una práctica o una normativa al respecto. Tanto los supervisores y directores de centros docentes como los estudiantes y sus familias, muchas veces con mecanismos no formales, evalúan el comportamiento de los docentes. Sin embargo, los criterios y las perspectivas de evaluación difieren mucho unos de otros (Roman, 2010).

En América Latina siguen siendo muy escasas las experiencias en materia de evaluación docente. Sin embargo, Chile y Colombia aparecen abundantemente citados en la bibliografía, y también recientemente, Perú (Vaillant D. , 2010). Pero, la gran constatación es que no existe unanimidad a la hora de establecer mecanismos de evaluación del desempeño docente. Una de las razones que justifican tal diversidad se relaciona con las normas que regulan la profesión. Otra de las comprobaciones que hemos podido hacer a través de la revisión de la literatura, es que - al igual que para incentivos- se trata de un tema cargado de ideología que genera grandes controversias y polémicas (Vaillant D. , 2012).

\section{Sistema de evaluación del desempeño docente en la ley de reforma magisterial no 29944}

El Sistema de Evaluación del Desempeño Profesional Docente, no contribuye al desarrollo de los maestros, en este campo, sino más bien prioriza el ahorro estatal y pretende evaluar las capacidades pedagógicas magisteriales sin considerar el contexto y las condiciones donde se realiza el proceso de enseñanza aprendizaje, hecho que va en contra de la meritocracia.

\section{Los fines del sistema de evaluación docente son:}

- Comprobar el grado de desarrollo de las competencias y desempeños profesionales del profesor en el aula, la institución educativa y la comunidad establecidos en los dominios del Marco de Buen Desempeño Docente.

- Identificar las necesidades de formación en servicio del profesor para brindarle el apoyo para la mejora de su práctica docente.

- Identificar a los profesores cuyo desempeño les da la posibilidad de acceder a los incentivos por excelencia y desempeño destacado (Artículo N44 del Reglamento de la Ley N²9944, Ley de la Reforma Magisterial).

- $\quad$ Establecer el Retiro o Cese definitivo de la Carrera Pública Magisterial para aquellos docentes que no aprueben la segunda evaluación de desempeño docente. (Ministerio de Educación, 2013).

En ese sentido, considero que dichos fines no promueven el crecimiento y desarrollo profesional de los docentes por las siguientes razones:

- $\quad \mathrm{Al}$ comprobar el grado de desarrollo de las competencias y desempeños profesionales del profesor (estándares mínimos) se busca que ingresen, asciendan o se mantengan los incompetentes.

- Al identificar a los profesores con desempeño destacado para brindarles incentivos por excelencia (estándares competitivos), se busca generar la competitividad entre los profesores y deteriorar la colegialidad entre los mismos.

- Al retirar o cesar definitivamente de la Carrera Pública Magisterial a aquellos que no aprueben la segunda evaluación extraordinaria de desempeño docente (enfoque negativo y punitivo de la evaluación), se busca identificar sólo las deficiencias en el rendimiento del profesor.

\section{Marco jurídico colombiano respecto a la estabilidad laboral docente}

La existencia simultánea de los dos decretos obedece a que en el año 2002 se creara un nuevo Estatuto Docente bajo el Decreto 1278, como política educativa se pretendieron transformar los procesos de ingreso, promoción y permanencia en la docencia en aras de un mejoramiento de la calidad la educación. Pero a su vez era necesario que se permitiera a los docentes del anterior Decreto 2277 de 1979 permanecer en sus puestos con sus derechos ya adquiridos. Es decir, "la permanencia de los docentes está dada por derecho" (MEN, 2008, p. 2). 
La implementación de estas reformas han estado acompañadas de resistencias sociales de los docentes estatales y sindicatos, las cuales se intensifican como forma de rechazo a estos procesos de reforma porque sienten que sus condiciones laborales corren riesgo dentro de estos nuevos marcos reglamentarios" (Bautista, 2009).

\section{De la evaluación docente}

- $\quad$ El concurso de méritos por el cual se ingresa al servicio educativo estatal.

- La evaluación de periodo de prueba. (4 meses)

- La evaluación anual de desempeños y competencias laborales;

- $\quad$ La evaluación de competencias que es para el ascenso en el escalafón docente. (MEN, 2007)

Comprendemos que la gran diferencia que se presenta en este punto es que a los docentes del Decreto 2277 no se les hace ningún tipo de evaluación, lo que genera una gran diferenciación y desigualdad, ya que para estos no existe la presión de la evaluación como condición para la permanencia o la calificación de su labor como condición para el ascenso, ni tareas extras como la recolección de "evidencias" ni diligenciamiento de formatos para dicha evaluación, lo que se podrían considerar como "tareas burocráticas". Contrario a los docentes del Decreto 1278 para quienes la evaluación es una condición que se debe preparar, por lo que constituye una tarea extra; o en algunos casos se aprecia como un cuestionamiento a su labor o un mecanismo de sanción. Además, la evaluación se argumenta bajo el eje de acción de mejoramiento de la calidad de la educación como política educativa propuesta desde el Decreto 1278 de 2002 o Estatuto de Profesionalización Docente, y "busca contribuir al mejoramiento de la labor de los educadores, propiciando en ellos la reflexión sobre su propio desempeño y su responsabilidad frente a la calidad de la educación" (MEN, 2007, p. 10).

\section{Ley del servicio profesional docente en la legislación mexicana}

En el caso específico de la Ley del Servicio Profesional Docente, llama la atención que este principio se vea violado en la Ley Reglamentaria (Presidencia de la República, 2013) en el capítulo VIII, del título "De la permanencia en el Servicio", exclusivamente en el último párrafo del artículo 53 al decir: "En caso de que el personal no alcance un resultado suficiente en la tercera evaluación que se le practique, se darán por terminados los efectos del Nombramiento correspondiente sin responsabilidad para la Autoridad Educativa o el Organismo Descentralizado, según corresponda”.

Además, la misma Ley señala que dicha evaluación será obligatoria, imposibilitado al docente alguna defensa en su beneficio. De todo lo indicado en la Ley lo que se describe a continuación hace presumir el despido: Desde el mismo instante en que la ley considera en su descripción que cuando los resultados de la tercera evaluación a la que se sujete el docente sean insuficientes, la autoridad educativa u órgano descentralizado en su caso, dará por terminado o rescindido el nombramiento correspondiente sin que exista responsabilidad alguna para la autoridad.

Pero lo más sorprendente es el nacimiento del concepto del docente como sujeto administrativo, que como lo describe (Santofimio, 2014): Los sujetos en el derecho administrativo, son aquellos que tienen un derecho o un deber, y que en el concepto más amplio es sinónimo de persona "sujeto de derecho". Es decir que es un nuevo concepto que habría que teorizar, un tópico al que los docentes deben de adaptarse, por el simple hecho de que de ahora en adelante ya no son trabajadores como tal, simplemente son sujetos administrativos, como lo describe su ley reglamentaria "servicio profesional docente".

Los juristas, es claro, dirán que el docente no deja de ser un trabajador al servicio civil del Estado por el simple hecho de prestar sus servicios intelectuales y recibir un pago como contraprestación, algo que se rompe en el momento en que el docente es condicionado a una evaluación y al no aprobarla, el Estado dará por terminados los efectos del Nombramiento correspondiente sin que exista responsabilidad del mismo. De la misma Ley nace el argumento de que al docente ahora no se le puede llamar trabajador, sino simplemente sujeto administrativo. Bajo este nuevo concepto, el docente pierde sus garantías laborales como el derecho a luchar por su reinstalación.

\section{Marco jurídico normativo sobre la estabilidad laboral en el sistema de desarrollo profesional docente chile}

En 1991 se dicta el Estatuto Docente (Ley No 19.070), que responde a las reivindicaciones reclamadas por los profesores, particularmente la estabilidad laboral y el esquema relativamente favorecido de salarios que gozaban, con anterioridad a 1980, al interior de la administración pública. En concreto, veremos que el Estatuto Docente crea una "carrera" para los profesores del sector municipal, la cual establece la titularidad en el cargo del docente.

El ingreso a la carrera docente en el sector municipal se efectúa mediante la incorporación del profesional de la educación a una dotación docente, sea en el carácter de titular o como contratado, incorporación que debe materializarse a través de un decreto alcaldicio de designación, en el caso del personal dependiente de Municipalidades o de un contrato de trabajo, en los demás casos.

Dotación docente es la cantidad de profesionales de la educación necesaria para atender el número de horas de trabajo y los cargos docentes, docentes - directivos y técnicos - pedagógicos que se requiere para el funcionamiento de cada uno de los establecimientos y para el conjunto de los que integran el sector municipal.

El Estatuto confiere a los profesionales de la educación municipal, estabilidad en las horas y funciones establecidas en los respectivos decretos de nombramiento o contratos de trabajo, según si se trata de titulares o de contratados, sin perjuicio de las causales de cesación establecidas en el propio Estatuto. 


\section{Régimen jurídico sobre la estabilidad laboral en el estatuto docente de argentina}

La reforma de la Constitución Argentina del año 1957 estableció en su artículo 14 el derecho del trabajador a la protección contra el despido arbitrario. Si bien antes de esa fecha ya se habían dictado leyes tuitivas en tal sentido, la reforma no solamente dio un respaldo doctrinal a las mismas, sino que además tuvo como consecuencia un aumento de las facultades de los jueces para controlar las medidas con las que se cumplía el mandato constitucional, permitiéndoles así que en casos extremos las invalidaran, como se analizará en el punto correspondiente.

El régimen vigente para la generalidad de los trabajadores, y que tiene como antecedente principal la ley 11729 del año 1932 , es el de la estabilidad relativa, esto es que en caso de despido sólo tienen derecho al cobro de una indemnización. La excepción son los representantes sindicales, para los cuales existe un sistema de estabilidad absoluta que se analiza en el punto correspondiente.(Poclava La Fuente, 1996). La Ley 13.552, publicada el 13 de octubre de 2006, consagra legislativamente un sentido y militado reclamo de los Trabajadores Docentes organizados: poseer una herramienta para la discusión de las condiciones de trabajo, en paridad de condiciones con la patronal. Así se construye colectivamente la Agenda Paritaria. Esta agenda la sostenemos con fuerza en las distintas Comisiones Técnicas que se constituyan: Consolidación de la gestión y organización del Trabajo escolar; Salud Laboral y Riesgos de Trabajo, Carrera Docente, nomenclador y escalafón; Salario Docente y Reglamentación, procedimientos y funcionamiento de la Paritaria, etc.

La "paritaria" constituye un paso fundamental en la consolidación de nuestra fuerza como trabajadores y en la concreción de una herramienta que nos es indispensable para poder discutir nuestros puestos de trabajo y para la conquista de todas las condiciones laborales que merecemos. (SUTEBA)

En el artículo 17 establece claramente: El personal Docente titular tendrá derecho a la estabilidad en el cargo, categoría, jerarquía y ubicación o destino, mientras se observe una conducta que no afecte la función y la ética Docente y conserve su eficiencia profesional y la capacidad psico-física necesaria para su desempeño, salvo en los casos establecidos en el presente Estatuto.

\section{Resultados}

De la tabla 1 podemos manifestar que; la legislación educativa del Perú establecida en la Ley de Reforma Magisterial 29944, el Estatuto de Profesionalización Docente de Colombia y la Ley de Servicio Profesional Docente de México, tienen muchas semejanzas y similitudes, puesto que en la Ley de Reforma Magisterial del Perú, está determinado taxativamente las condiciones para la permanencia dentro de la ley, dentro de los cuales establece la evaluación de desempeño docente como única condición para su permanencia. Además, que tiene la característica de ser obligatoria, el cual se realiza cada tres años. Es decir, que si algún maestro no se presenta a estas evaluaciones programadas tendrán como sanción la exclusión o el término de sus funciones como docente, retirándolos de la carrera docente.

Por su parte, en el Estatuto de Profesionalización Docente de Colombia, no están determinados taxativamente las condiciones de permanencia, sino que las deducimos del análisis de los artículos contenidos en la norma; por tanto, éste tiene una semejanza en la conceptualización realizada por los legisladores peruanos y mexicanos; pues, manifiesta en el art. 16 "el carácter profesional de los educadores depende de la idoneidad en el desempeño de su gestión y de las competencias demostradas como fundamento principal para el ingreso, permanencia y promoción en el servicio" (MEN, 2008, p. 2).

Cabe mencionar que en la legislación educativa colombiana existe dos normas que regulan la carrera docente y que ambos decretos están vigentes. "la permanencia de los docentes del Decreto 2277 de 1979 está dada por derecho", mientras que "la permanencia de los docentes del 1278 del 2002, está dada por condicionamientos como la evaluación de desempeños"(MEN, 2008, p. 2). Es decir, que los docentes del Decreto 2277 permanecerían en sus puestos bajo el argumento del derecho, que la implementación del nuevo decreto no implicaría la pérdida de su condición con los beneficios ya alcanzados y que éstos tampoco permitirían que se vulneraran sus derechos, ya que la permanencia de los docentes no está condicionada por la evaluación ya que ésta no existe y el ascenso depende de los años de antigüedad y la capacitación por créditos especialmente en Programas de Formación Permanente para Docentes -PFPD- u otros programas de posgrado o especialización, lo que significa que la permanencia es por capacitación y antigüedad. En contraposición, en el Decreto 1278 de 2002 la permanencia está condicionada a la evaluación que es permanente y obedece a la superación del periodo de prueba, la evaluación anual por desempeños y competencias, también depende de la idoneidad para ejercer el cargo que debe ser demostrada en las evaluaciones mencionadas, además de las habilidades pedagógicas y didácticas en la enseñanza, la capacidad en la resolución de problemas y el nivel de conocimiento.

Ley General Del Servicio Profesional Docente México, le brinda un estudio más importante, puesto que, dentro de la legislación, ocupa un capítulo separado considerando las condiciones para su permanencia dentro de la carrera docente. El cual tiene como única condición, al igual que en la legislación peruana y colombiana, a la evaluación de desempeños de manera periódica y con una característica especial de carácter obligatorio, que si no se cumpliera o no se formara parte de dichos procesos tendrían como sanción la destitución o exclusión de la carrera docente.

Por consiguiente, “en América Latina, la implementación de estas reformas han estado acompañadas de resistencias sociales de los docentes estatales y sindicatos, las cuales se intensifican como forma de rechazo a estos procesos de reforma porque sienten que sus condiciones laborales corren riesgo dentro de estos nuevos marcos reglamentarios" (Bautista, 2009, p. 112). 
Tabla 1

Semejanzas para la permanencia en la carrera docente

SEMEJANZAS

\section{LEY DE REFORMA MAGISTERIAL} PERÚ

\section{CAPÍTULO VI}

\section{Permanencia y ascenso en la Carrera Pública Magisterial}

Art. 23. La evaluación del desempeño docente es condición para la permanencia, en concordancia con el art. 28 de la presente Ley.

Es obligatoria y se realiza como máximo cada tres años.

Los profesores que no aprueben en la primera oportunidad reciben una capacitación destinada al fortalecimiento de sus capacidades pedagógicas. Luego participan en una evaluación extraordinaria. En caso de que no aprueben esta evaluación, nuevamente son sujetos de capacitación. Si desaprueban la segunda evaluación extraordinaria son retirados de la Carrera. Entre cada evaluación extraordinaria no puede transcurrir más de (12) meses.

\section{ESTATUTO DE PROFESIONALIZACIÓN DOCENTE COLOMBIA}

Art. 16. La carrera docente se basa en el carácter profesional de los educadores; depende de la idoneidad en el desempeño de su gestión y de las competencias demostradas; garantiza la igualdad en las posibilidades de acceso; y considera el mérito como fundamento principal para el ingreso, la permanencia, la promoción en el servicio y el ascenso.

Art. 18. Gozarán de los derechos y garantías de la carrera docente los educadores estatales que sean seleccionados mediante concurso, superen satisfactoriamente el período de prueba, y sean inscritos en el Escalafón. Siempre que haya pasado el periodo de prueba 1 año.
LEY GENERAL DEL SERVICIO PROFESIONAL DOCENTE MÉXICO

\section{CAPÍTULO VIII}

\section{De la Permanencia en el Servicio}

Artículo 52. Las Autoridades Educativas y los Organismos Descentralizados deberán evaluar el desempeño docente y de quienes ejerzan funciones de dirección o de supervisión en la Educación Básica y Media Superior que imparta el Estado.

\section{La evaluación a que se refiere el párrafo anterior será obligatoria.}

Como ya hemos esgrimido anteriormente, nuestra legislación educativa respecto al maestro, difiere sustancialmente de las legislaciones de Argentina y Chile. El Estatuto Docente de Argentina, establece claramente en su art. 65 que el docente tendrá carácter de titular siempre y cuando apruebe el examen psico-físico; es decir, que el docente no estará sumido a una evaluación de capacidades, aptitudes ni conocimientos para su permanencia dentro del Estatuto Docente, sino que se basará en un examen de carácter médico. Dentro de los cuales se tomará en cuenta el desarrollo físico del docente como también de la situación psicológica en la que se encuentre el docente para el ejercicio de la profesión.

Por su parte, el Sistema de Desarrollo Profesional Docente de Chile, no lo prescribe de manera precisa, pero haciendo un análisis del art. 18, llegamos a la conclusión de que los docentes para su permanencia en dicho régimen, cada uno es responsable de su desempeño y que deberán someterse a los procesos de evaluación y que necesariamente ante los resultados de estas conclusiones tendrán derecho y podrán recurrir contra una apreciación o evaluación de su desempeño si la estima infundada. Es decir, que el maestro que no se encuentre conforme con una calificación sobre su desempeño podrá refutarla y pedir nueva calificación. Además, que la obtención de ciertos resultados no acarrea por ningún motivo el cese en la permanencia de la carrera docente, por consiguiente, las dos legislaciones del derecho comparado son más flexibles para el docente, lo que le permite tener tranquilidad o estabilidad laboral dentro del desarrollo profesional. 


\begin{tabular}{|c|c|c|}
\hline \multicolumn{3}{|c|}{ DIFERENCIAS } \\
\hline $\begin{array}{c}\text { LEY DE REFORMA MAGISTERIAL } \\
\text { PERÚ }\end{array}$ & $\begin{array}{c}\text { ESTATUTO } \\
\text { DOCENTE ARGENTINA }\end{array}$ & $\begin{array}{c}\text { SISTEMA DE } \\
\text { DESARROLLO } \\
\text { PROFESIONAL DOCENTE } \\
\text { CHILE }\end{array}$ \\
\hline $\begin{array}{l}\text { Art. 23. La evaluación del desempeño } \\
\text { docente es condición para la permanencia, } \\
\text { en concordancia con el art. } 28 \text { de la presente } \\
\text { Ley. } \\
\text { Es obligatoria y se realiza como máximo } \\
\text { cada tres años. } \\
\text { Los profesores que no aprueben en la primera } \\
\text { oportunidad reciben una capacitación } \\
\text { destinada al fortalecimiento de sus } \\
\text { capacidades pedagógicas. Luego participan } \\
\text { en una evaluación extraordinaria. En caso de } \\
\text { que no aprueben esta evaluación, } \\
\text { nuevamente son sujetos de capacitación. Si } \\
\text { desaprueban la segunda evaluación } \\
\text { extraordinaria son retirados de la Carrera. } \\
\text { Entre cada evaluación extraordinaria no } \\
\text { puede transcurrir más de (12) meses. }\end{array}$ & $\begin{array}{l}\text { Art. 65. La designación del personal } \\
\text { Docente tendrá carácter de titular interino } \\
\text { hasta que, el mismo apruebe el examen } \\
\text { psico-físico y fuese calificado con seis (6) } \\
\text { puntos como mínimo. Esta calificación } \\
\text { deberá efectuarse el primer año lectivo } \\
\text { durante el cual no se halle comprendido en } \\
\text { las causales previstas en el Art. } 130 . \\
\text { Cesarán en el cargo los Docentes que no } \\
\text { aprobaran el examen psico-físico o no } \\
\text { alcanzaran la calificación mínima exigida. } \\
\text { En estos casos no podrán ser incluidos en } \\
\text { los registros de aspirantes al ingreso en la } \\
\text { docencia, hasta tanto sean declarados aptos } \\
\text { por la junta médica o hayan transcurrido dos } \\
\text { (2) años desde el momento del cese. }\end{array}$ & $\begin{array}{l}\text { Artículo 18: Los profesionales } \\
\text { de la educación son } \\
\text { personalmente responsables de } \\
\text { su desempeño en la función } \\
\text { correspondiente. }\end{array}$ \\
\hline
\end{tabular}

$\mathrm{Al}$ referirnos a este tema, en la tabla 3, coincidentemente tenemos que manifestar, que existe una similitud casi exacta de ley peruana con las leyes colombianas y mexicanas; al no abordar de manera clara y precisa los presupuestos para que el tema de la estabilidad laboral sea tomado como un derecho y una garantía ante una posible violación de derechos laborales. Así la Ley de Reforma Magisterial 29944 del estado peruano hace referencia en el art. 41 inciso d, que los profesores tienen derecho a la estabilidad laboral, pero esta determinación está sujeta a una serie de condiciones que la propia ley establece, que no es otra cosa que estar sujetos a evaluaciones permanentes, lo que significa que si uno no participa en dichos procesos o no logra tener un calificativo eficiente o no aprueba las tres evaluaciones al que tienen derecho de poder acceder, éste podrá ser retirado y excluido de la carrera docente.

Por tal razón, este derecho que tenemos todos los docentes trabajadores del sector estatal, estamos desprotegidos y somos muy vulnerables, puesto que ya no contamos con una estabilidad laboral absoluta, como si lo teníamos en la legislación anterior de la Ley del Profesorado 24029 y que a su vez la constitución política de 1979 lo establecía de manera clara y precisa. A su vez, el Estatuto de Profesionalización Docente de Colombia, al respecto, hace una referencia muy sutil y camuflada para dar a conocer este derecho laboral, tanto así que no está determinado dentro del ordenamiento jurídico, pues lo menciona en el capítulo referido a los derechos y deberes de los docentes colombianos, específicamente en el art. 37 inciso c, donde manifiesta que tienen derecho a permanecer en los cargos y funciones, mientras su trabajo y conducta sean enteramente satisfactorios. Es decir, que en primer lugar tendrán que superar el periodo de prueba al que han sido subsumidos y que en segundo lugar, hayan aprobado las diversas evaluaciones de conocimientos, aptitudes, etc., para que como consecuencia de un largo trabajo y sacrificio, puedan gozar no de estabilidad laboral sino de tranquilidad momentánea en el ejercicio de la profesión; caso contrario estaremos ante un despido, exclusión o término inminente de la relación laboral docente (Decreto Ley 1278 del 2002).

Dada la existencia de dos regímenes de carrera docente en Colombia, cada una responde a realidades diferentes, realidades históricas y sociales. El Decreto 2277 de 1979, habla que, la estabilidad de los docentes vinculados mediante este decreto se da una vez que ingresan en el servicio educativo estatal, por cuanto los derechos de carrera docente se obtienen -de acuerdo con este estatuto- una vez el educador cuente con inscripción previa en el escalafón docente, sea "designado en propiedad" y tome posesión de dicho cargo(Ministerio de Educacion Nacional, 2008). Como se anotó anteriormente, durante la vigencia de esta norma para el ingreso al servicio educativo estatal se estableció de forma reglamentaria el concurso de méritos, mediante el decreto 1706 de 2009 , artículo $14^{\circ}$. Se estableció que los nombramientos del personal docente y directivo docente nacional y nacionalizado, se harían por concurso, convocado y realizado de acuerdo con la reglamentación que expidiera el Ministerio de Educación Nacional. El mismo decreto garantiza la permanencia en el servicio, en el Art. 31 (Permanencia).

El educador tiene derecho a permanecer en el servicio mientras no haya sido excluido del escalafón o no haya alcanzado la edad de sesenta y cinco (65) años para su retiro forzoso. Y también en el Art. $28^{\circ}$ (Estabilidad). El educador escalafonado al servicio 
oficial no podrá ser suspendido o destituido del cargo, sin antes haber sido suspendido o excluido del escalafón, sino por ineficiencia profesional o mala conducta comprobada, en los términos establecidos. La estabilidad era, así entendida un derecho casi absoluto, en el que era excepcional la desvinculación, adicionalmente la imposibilidad de evaluación no permite evidenciar el mérito para la permanencia en el servicio, en contravía a lo dispuesto en la Constitución Política Nacional. Por su parte, en la Ley General del Servicio Profesional Docente de México, corre la misma suerte que las legislaciones de Perú y Colombia, tampoco está determinado 4, pero haciendo un análisis podemos deducir lo siguiente: se puede apreciar casi la misma terminología y objetivos trazados en las normas peruanas y colombianas en cuanto al tratamiento del tema en mención, puesto que no le brinda mayor importancia al estudio del tema sino más bien se ha dejado de lado este tema. Pero haciendo un análisis exhaustivo hemos descubierto la verdadera intencionalidad de la ley, en el apartado dedicado a las evaluaciones que un docente tiene que cumplir para seguir formando parte de la carrera docente (art. 53)(Presidencia de la Republica, 2013). Además, la misma Ley señala que dicha evaluación será obligatoria, imposibilitado al docente alguna defensa en su beneficio.

De todo lo indicado en la Ley lo que se describe a continuación hace presumir el despido: Desde el mismo instante en que la ley considera en su descripción que cuando los resultados de la tercera evaluación a la que se sujete el docente sean insuficientes, la autoridad educativa u órgano descentralizado en su caso, dará por terminado o rescindido el nombramiento correspondiente sin que exista responsabilidad alguna para la autoridad. Es decir, el docente no podrá ejercer su derecho a reinstalación o indemnización constitucional, como antiguamente consagraba la Constitución, lo que es más violatorio a la vez, dejarlo sin protección o al amparo constitucional. Es claro que, en la Ley General del Servicio Profesional Docente, la violación es flagrante al principio de la estabilidad en el empleo, al condicionar al trabajador docente a las tres futuras evaluaciones para su permanencia. Desde el punto de vista jurídico y según (Dávalos, 2011), la estabilidad en el empleo es un principio que tiene por finalidad proteger a los trabajadores en el empleo, a fin de que tengan, en tanto lo necesiten y "así lo deseen, una permanencia más o menos duradera. Sin este principio los postulados de igualdad, de libertad y el trabajo como un derecho y un deber sociales, quedan sin sustento".

Tabla 3

Semejanzas sobre la estabilidad laboral en la carrera docente

\section{SEMEJANZAS}

\section{LEY DE REFORMA MAGISTERIAL PERÚ \\ ESTATUTO DE PROFESIONALIZACIÓN DOCENTE COLOMBIA \\ LEY GENERAL DEL SERVICIO PROFESIONAL DOCENTE MÉXICO}

\begin{tabular}{ll}
\hline Artículo 41. & Derechos, deberes, prohibiciones, inhabilidades \\
e incompatibilidades.
\end{tabular}

Los profesores tienen derecho a:

Estabilidad laboral sujeta a

las condiciones que

establece la presente Ley.

(Evaluaciones cada 3 años)

(está determinado)

\begin{abstract}
Art. 37. Derechos. Además de los contemplados en la Constitución, en la ley, en el Código Disciplinario Único y en los reglamentos vigentes, para todos los servidores públicos, los docentes y directivos docentes al servicio del Estado tendrán los siguientes derechos:
\end{abstract}

\footnotetext{
c. Permanecer en los cargos y funciones mientras su trabajo y conducta sean enteramente satisfactorios y realizados conforme a las normas vigentes, no hayan llegado a la edad de retiro forzoso o no se den las demás circunstancias previstas en la ley y en este decreto.
}

\begin{abstract}
Art. 53. Cuando en la evaluación se identifique la insuficiencia en el nivel de Desempeño, el personal se incorporará a los programas de regularización.
\end{abstract}

Tendrá la oportunidad de sujetarse a una segunda oportunidad de evaluación en un plazo no mayor de doce meses, la cual deberá efectuarse antes del inicio del siguiente ciclo escolar.

De ser insuficientes los resultados, el evaluado se reincorporará a una tercera evaluación que se llevará a cabo en un plazo no mayor de doce meses. En caso de que el personal no alcance un resultado suficiente, se darán por terminados los efectos del Nombramiento.

En la tabla 4 se puede apreciar, que los ordenamientos jurídicos de los tres países en mención determinan taxativamente el tratamiento sobre la estabilidad laboral, pero existe dentro de los cuales, diferencias abismales que hacen que este principio de protección al trabajador sea vulnerado por los empleadores (el Estado). Primero nos referiremos a la normatividad peruana, que no se le da un debido tratamiento, puesto que está considerado dentro de los derechos del maestro y que para su cumplimiento requiere del cumplimiento de ciertas condiciones que están determinado por una serie de evaluaciones que tienen que ser superadas para que se haga efectivo la dichosa "Estabilidad Laboral", y que en caso de no superarlo se estaría perdiendo dicho derecho.

Cosa distinta ocurre con la legislación Argentina, donde en comparación con la legislación peruana, se le da un tratamiento especial, considerándolo como una institución jurídica muy importante; puesto que está determinado en el capítulo V, lo que quiere 
decir que para dicha legislación es de suma importancia. El art. 17 refiere que, el personal docente tendrá derecho a la estabilidad en el cargo, categoría, jerarquía y ubicación o destino, mientras se observe una conducta que no afecte la función y ética docente y la capacidad psico-física necesaria para su desempeño. Es decir, que el ordenamiento jurídico no establece ningún tipo de evaluación que ponga en peligro la permanencia en la carrera docente, más por el contrario brinda una protección que garantiza plenamente el servicio docente; además brinda criterios para la perdida de la estabilidad en el art. 18. a) Cuando el Docente reúna los requisitos exigidos para obtener los beneficios jubilatorios máximos. b) Por sanción expulsiva dispuesta conforme con las normas de este Estatuto. Lo que claramente no ocurre en las legislaciones del Perú, Colombia y México.

Por su parte la normatividad Chilena, también difiere de la legislación educativa peruana, colombiana y mexicana, puesto que en su Sistema de Desarrollo Docente, después de la última reforma del año 2016, ha mantenido la redacción normativa de su legislación anterior, puesto que sigue manteniéndose a la estabilidad laboral como un derecho del personal docente específicamente en su art. 36 que establece: los profesionales de la educación que tengan la calidad de titulares tendrán el derecho a la estabilidad en las horas y funciones establecidas, a menos que deban cesar por alguna causal de expiración establecida. Es decir, que tampoco existe ningún tipo de evaluación para la permanencia en el cargo y mucho menos existe el riesgo de pérdida de la estabilidad laboral, pues este está protegido taxativamente por la legislación educativa que le brinda garantía en el desarrollo de la profesión y que solamente se podrá esta condición por causales establecidas en la norma en mención.

Tabla 4

Diferencias de la estabilidad laboral en la carrera docente

\begin{tabular}{ccc}
\hline & DIFERENCIAS & SISTEMA DE DESARROLLO \\
\hline LEY DE REFORMA & ESTATUTO & PROFESIONAL DOCENTE \\
MAGISTERIAL PERÚ & DOCENTE ARGENTINA & CHILE \\
\hline
\end{tabular}

\section{Artículo 41.}

Los profesores tienen derecho:

CAPÍTULO V

DE LA ESTABILIDAD

d. Estabilidad laboral sujeta a las condiciones que establece la presente Ley. (Evaluaciones cada 3 años)
Art. 17. El personal Docente titular tendrá derecho a la estabilidad en el cargo, categoría, jerarquía y ubicación o destino, mientras se observe una conducta que no afecte la función y la ética Docente y conserve su eficiencia profesional y la capacidad psico-física necesaria para su desempeño, salvo en los casos establecidos.
Derechos del personal docente

Artículo 36: Los profesionales de la educación que tengan la calidad de titulares, tendrán derecho a la estabilidad en las horas y funciones establecidas en los decretos de designación o contratos de trabajo, según corresponda, a menos que deban cesar en ellas por alguna de las causales de expiración de funciones establecidas en este Estatuto.

\section{Conclusiones}

Las sociedades a lo largo de la historia han mantenido el oficio del maestro como un elemento primordial del sistema educativo latinoamericano. No obstante, a través del tiempo, su significado y función social se ha modificado de acuerdo con las grandes transformaciones de los países. Las políticas de reforma educativa cambiaron de orientación, condiciones y enfoques con respecto al trabajo y la identidad docente, creándoles una situación de temeridad, inestabilidad no solo en el desempeño de su labor sino también en el ámbito familiar. Estas condicionantes, podrían argumentarse como una vulneración que resta el derecho a la "estabilidad laboral" en comparación con sus legislaciones anteriores; en tanto que determinan periódicamente su continuidad de acuerdo a los resultados de sus evaluaciones, que lo ubican en condiciones profesionales distintas a sus pares.

El tratamiento que se le brinda a la institución jurídica de la estabilidad laboral docente, como condición de permanencia en el puesto de trabajo; en el ámbito del derecho comparado, es muy diverso; puesto que, en los estatutos de Argentina y Chile, la permanencia de estos se encuentra prácticamente resuelta en lo formal, dado que sus causales de retiro de la carrera son disciplinarias o por cumplir el tiempo de servicio para la jubilación. Pero también, en algunas legislaciones como la nuestra, se ha implantado otro mecanismo mucho más punitivo que los demás. Es así que en las legislaciones del Perú, Colombia y México, a la nueva generación de docentes que se empieza a configurar en la actualidad les espera una permanencia condicionada a los resultados de su desempeño dentro del aula y en la institución educativa, producto del contexto de competencia que instalan estas preocupaciones estatales por mejorar la calidad educativa. A pesar del valor que toman las evaluaciones de desempeño en la permanencia de los docentes, no es posible reducirla a este único factor. Conforme a su satisfacción personal y a la motivación que encuentren en su entorno educativo, los profesores pueden desear permanecer o no en el cargo. Sin embargo, esto es un aspecto que, en general en las políticas, no sólo del país, sino de Latinoamérica, se encuentra ausente.

El principio de estabilidad laboral involucra también el principio de seguridad jurídica para el trabajador. Ello es así, ya que evita que el trabajador se encuentre en un estado de constante riesgo de perder su empleo, de lo contrario, se ocasionaría en el trabajador y su familia de manera inmediata un cambio constante en su estilo de vida y quizá de lugar de residencia. Es así que la normatividad 
de algunos países como el de Colombia o México, no lo regulan de manera clara y precisa, pues lo que seguramente pretende los estados es dejar de lado o no aplicar este principio. Lo que en el Perú está determinado taxativamente, pero con una limitante que se concretizará siempre y cuando se aprueben las evaluaciones obligatorias ofrecidas. Cosa muy distinta ocurre en las legislaciones de Argentina y Chile, pues estos mantienen una concepción más principista y garantista de acuerdo al desenvolvimiento en la función docente.

Es así que la Ley de Reforma Magisterial del Perú, el Estatuto de Profesionalización Docente de Colombia y la Ley General de Servicio Profesional Docente de México, mantienen una semejanza y similitud muy clara respecto al ingreso, permanencia, estabilidad laboral y término en la carrera docente; lo que difiere en gran medida con las legislaciones del Sistema de desarrollo Profesional Docente de Chile y el Estatuto Docente de Argentina, puesto que en esencia, aún mantienen una legislación garantista de los derechos del docente respecto a la permanencia en el cago y su estabilidad laboral.

\section{Referencias}

Bautista, M. (2009). La Profesionalización Docente en Colombia. Revista Colombiana de Sociología, 112.

Dávalos, J. (2011). Derecho individual del trabajo. México: Porrúa.

Marcenaro, R. (1995). El Trabajo en la Nueva Constitución. Lima, Perú: Cultural Cuzco S.A. Editores.

MEN. (Abril de 2008). Ministerio de Educación Nacional, Estatuto de Profesionalización Docente, Decreto 1278 de 2002. Recuperado el 27 de Octubre de 2015, de http://www.colombiaaprende.edu.co/html/productos/1685/articles-161031_archivo_3.pdf.

Ministerio de Educación. (2013). Ley de Reforma Magisterial 29944 y Reglamento de la Ley D.S. 004-2013--ED. Lima: Ministerio de Educación.

Ministerio de Educacion Nacional, R. d. (2008). Recuperado el 26 de octubre de 2015, de mineducacion.gov.co: www.mineducacion.gov.co - atencionalciudadano@mineducacion.gov.co

Neves, J. (2001). Derecho al Trabajo y Derecho de Estabilidad en el Trabajo. Lima: Revista Derecho y Sociedad.

Peña, S. (2011). Metodología de la Investigación. Chile: Editorial Universidad Nacional Andrés Bello.

Plá, A. (1968). Los Principios del Derecho del Trabajo. Buenos Aires: Ediciones Depalma.

Poclava, J. C. (1996). Ley de Contrato de Trabajo. Manuales de Jurisprudencia. Buenos Aires: La Ley S.A.

Presidencia de la Republica. (2013). Ley General del Servicio Profesional Docente. Diario Oficial de la Federación. Recuperado el 29 de Octubre de 2015, de www.presidencia.gob.mx: http://www.presidencia.gob.mx/reformaeducativa/assets/downloads/leygeneral-del-servicio-profesional-docente.pdf

Ragin, C. C. (1994). La Construcción de la Investigación Social. Bogotá: Sage Publicaciones Derecho y Sociedad.

Roman, M. (2010). La Voz Ausente de Estudiantes y Padres en la Evaluación del Desempeño Docente. Santiago de Chile: PREAL.

Santofimio, J. O. (2014). Acto Administrativo. Procedimiento, Eficacia y Validez. Recuperado el 25 de Setiembre de 2015 , de es.scribd.com: http://es.scribd.com/doc/72847015/ACTO-ADMINISTRATIVO-PROCEDIMIENTO-EFICACIA-Y-VALIDEZJAIME-ORLANDO-SANTOFIMIO.

Toyama, J. (2001). Los derechos Laborales en las Constituciones de 1979 y 1993. Balance de la Reforma Laboral. Lima: Sociedad Peruana de Derecho del Trabajo y de la Seguridad Social.

Vaillant, D. (2012). La Gobernanza Educativa y los Incentivos Docentes: El caso de Chile y Uruguay. Uruguay: Revista Uruguaya de Ciencia Política.

Vaillant, D. y Rossel, C. (2006). Maestros de Escuelas Básicas en América Latina: Hacia una Radiografía de la Preofesión. Santiago de Chile: PREAL. 